\title{
Queering a Queer Novel: Is There Something Queer about Running?
}

\author{
Donald Christopher Risker
}

Webster University, USA

Copyright $\bigcirc 2017$ by authors, all rights reserved. Authors agree that this article remains permanently open access under the terms of the Creative Commons Attribution License 4.0 International License

\begin{abstract}
This investigation examined Patricia Nell Warren's gay classic Front Runner as a queer text. Queer theory has been traditionally applied to heterosexual contexts and texts to demonstrate similarities between gay behavior and heteronormative behavior. This investigation applied queer theory to Front Runner to determine what, if anything is queer about being a gay Olympic-level runner. While there is much in Front Runner that relates to American gay culture in the 1970s, this investigation focused on the running passages in Front Runner to assess the effect of applying queer theory to a queer novel. The investigation found that some passages were consistent with heteronormative athletic portrayals, while other passages emphasized the gay protagonist as tough and competitive, as if to establish a hetero-normative machismo for the protagonist. Other passages were simply typical of hetero-normative sport literature.
\end{abstract}

Keywords Gender Studies, Queer Theory, Gay Literature

\section{Introduction}

Front Runner holds a contradictory place in gay literature today. Many gay men regard Front Runner as the first breakthrough validation of love-seeking gay behavior, others find it jaded or out of date [1]. Yet other gay critiques find it difficult to identify with the Olympic class runners featured in Front Runner: "The Front Runner's heroic masculine characters... are not the faggots that most of us know" [2]. The stark contrast among the different perspectives may in part reflect the complicated and evolutionary nature of gay [homosexual] studies and queer theory.

Queer theory has co-evolved with qualitative research [3]. Initially, gay or homosexual research was interested in the phenomenon of homosexuality as a subject of study. Researchers sought to objectively study the homosexual as an aberrant social phenomenon. Early researchers relied on quantitative methods. These methods were resisted because the research emphasized gay behavior as a deviant outcome. However, the gay community felt that quantitative methods failed to understand and respect the lived gay experience. The gay community insisted that gay life was a life lived, not to be measured or to be considered aberrant. Researchers adapted by adopting qualitative research methods for the study of 'homosexuality' to reflect a more holistic approach. As research progressed, method and subject co-evolved, eventually coming to occupy a similar intellectual space. Queer theory remains an important domain of qualitative research [4].

Queer theory insists that same sex attraction is not something unique to be studied, but simply about the expression of desire toward the human body. Qualitative research concedes that a life or life experience per se cannot be rendered whole even through qualitative methods, though a representation human experience can be credibly attempted. However, some queer theorists continue to reject this non-discriminate definition of queer theory because it strips away or denies the uniqueness of the queer experience, an experience that the gay community and gay critics fought hard to construct and lay claim to.

\section{Materials and Methods}

In order to answer the question, "Is there something queer about running?" the competitive running sequences in Front Runner were selected for close reading and critical analysis. As Reference [3] shows queer theory has co-evolved over time with gay/gender studies and methods. This evolution began with the refutation of quantitative studies of the homosexual as a bizarre phenomenon, moved through sexual identity orientation, and most recently merged with literary theory as simply another way of interpreting or challenging dominant cultural patterns. This final expression of queer theory freed it from more narrow theory constraints and sexual identity orientation. Garber [5] further underscores this perspective by positing that "No analysis will fit the shape of desire..." And Halperin [6] asserts that "Queer is by 
definition whatever is at odds with the normal, the legitimate, the dominant. There is nothing in particular to which it necessarily refers to." General application of this view of queer theory to a text encourages breaking down binary thinking that necessarily sorts human behavior strictly into heteronormative or gay categories. But what is the theoretical result of reversing the theory? Are there heteronormative aspects to the gay classic Front Runner? Or more simply stated, is there something queer about running?

\section{Results}

Front Runner is an extended narrative by Harlan Brown, a college track coach and closeted gay. Brown acts as the authorial voice of the author, Patricia Warren. Billy Sive, the protagonist and Olympian to be, is introduced in highly athletic terms by his coach and soon to be lover, Harlan Brown. Brown describes Sive's stride as "effortless." He observes him as having an "eerie, slow-motion quality" that appears "ghostly" [7]. He can hardly "hear his spikes stir the cinders," and sees him as "almost unreal" [8]. Coach Brown's musings toward this world class athlete are reminiscent of the natural talent of Malamud's Roy Hobbs. It is the literary framing of the found or discovered athlete: "He was that idea of a runner that haunts the minds of track people" [9]. Even his racing style is rare. Billy is a front runner. According to Brown, "He was at his coolest in a big race, and he was savagely competitive. He would, as I said, kill himself to stay in front" [10]. Runners expend approximately eight percent more energy to run from the front. Billy not only runs hard, but he races in the most physically demanding style possible. Through Brown, Warren makes the case that a gay runner can be as tough as anyone, especially as tough as anyone heteronormative. She suggests that Billy runs out front to prove "some worth as a man and as a human being...through his hard racing" [11].

Billy's first European race on the world stage of running is a demonstration of the front running strategy and its vulnerability. Billy "bursts" to the front where he stays until the very last moment of the race [12]. As Billy slows, he is passed by two of his competitors, barely finishing in third. Coach Brown concedes that "I knew in my heart that he didn't have the stamina yet to hold them off' [13]. Here Billy is the typical journey man runner learning his trade. However, at dinner following the race, Billy's Finnish competitor states that Billy has sisu, the Finnish word for toughness, a significant recognition, edging him closer to the hyper-masculine hetero-normative ideal.

When Billy competes in Spain, he is called a maricon. Word of his sexual orientation and relationship with Coach Brown precedes him. The race crowd is hostile and homophobic. The Spanish runners are described as under "terrible pressure" to beat the maricon. But we are reassured by Coach Brown that these are the conditions under which Billy was "his most cold blooded," yet another attestation to
Billy's toughness [14]. The prediction is borne out. Billy wins the race easily as the crowd "whistles" for Billy's victory and "whistles" for the Spanish runners' loss [15]. However, not much later in the United States, enmity is audible and visible among all the participants, including the spectators. The race begins with the crowd "screaming for blood" [16]. Elbows are thrown during a very partisan and contentious race. Insults are exchanged at the end of the race between another gay runner and the openly homophobic runner, Dellinger: "you whore" and you "straight pig" [17]. The dramaturgy between gay and straight is expressed in starkly binary terms. While in-groups and out-groups are often dramatized sport contests, something very specific is being expressed here. Gays are assumed to be promiscuous and straights insensitive. Stereotypes perhaps linger today.

The final running episodes in Front Runner are the most significant and dramatic, the Olympic Trials and the Olympics themselves. The heteronormative/gay binary has been blurred by a 'symbolic' wedding between Harlan Brown and Billy. As they enter the stadium at Olympic Trials a gay friendly runner exclaims "Christ, you guys ought to have a couple of body guards" [18]. The comment foreshadows future events, but the Olympic Trials present their own set of problems. In the 5,000 meters, Billy is knocked down by his archrival Dellinger. Billy loses a shoe and his glasses. Of course, for drama there must be an antagonist. Dellinger is not only antagonistic, but also a cheat. And his cheating devises a greater challenge to Billy, not an uncommon technique in sport literature. Not only must the protagonist prevail, but he or she must prevail under conditions of extreme or unfair duress. Initially, Billy is called for the foul, and Harlan sees that Billy looks “... sick with shock and heat...His eyes were wet but he wasn't crying" [19]. However, gay Billy is he can clearly handle the hurt.

The missed call by the officials is made more egregious by their refusal to review it. The one sympathetic runner, Stella, declares "It's the crookedest thing I've ever seen" [20]. Injustice is also a familiar trope in hetero-normative literature: A hero is cheated out of a victory or reward because of misperception or malice. It sets the stage for resentment, and possibly another cycle of conflict, revenge, and resolution, but not in Front Runner. After Billy quietly wins the 5,000 meters, it is learned that under threat of judicial review, the track officials reverse the foul and disqualify Dellinger from the 10,000 meters. Billy is set to run the challenging double of 5,000 and 10,000 meters in the Olympics.

The Olympic 10,000 meters race is simply described. Billy is pitted against Sepponan again. The crowd, aside from "going berserk," fails to be a factor, unlike the trials where partisanship prevailed [21]. Billy simply outkicks Sepponan with enough to spare for the victory. The story line for the race is simply two great runners going head to head, with the protagonist winning. Brown observes "The entire stadium was on its feet applauding, which always happens 
when a popular favorite wins" [22].

The 5000 meters is a different matter. Sepponan considers the distance to be his best, and Billy's homophobic nemesis Dellinger is also contesting it. Brown concedes the outcome: "Very likely he'll [Billy] get silver or a bronze here. It won't be a great tragedy, really. He will have made his point" [23]. But what is his point? Is it his point that he is a world class Olympic runner? Is it his point that he is both a world class Olympic runner capable of suicidal pacing and also gay? Is it all of these? Would a hetero-normative athlete have a point to make beyond winning? The competition heats up quickly. Sepponan and Dellinger dash and slash behind Billy's front running. Sepponan drops Dellinger, and the race becomes a headlong battle of intense running. Brown describes his sensations at the decisive duel at viewing the two runners "actually they both awed me," and "we were watching some elemental force of nature, a storm at sea, a volcano erupting, an earthquake" [23]. When Billy finally breaks through Brown speculates: "With whatever his final edge was, gay desperation, or just vitamin E pills, he had broken the iron Finn" [24].

"Gay desperation" and "vitamin E pills" seem incommensurate. The first seems to be a fundamental need to prove himself, though gay, as tough as any runner; the second, a quixotic advantage, impossible to prove as cause for an edge. As compelling as "gay desperation" may be, the triviality of vitamin E pills may be closer to the explanation for elite superiority. In a single moment it could be anything or nothing. But it matters little, for two meters later, Billy is dead, having been shot by a man from Brown's youth. A man who has become twisted by repressed same-sex attraction and the duel forces of hate and love. Thus, Front Runner drives home the consequences of self-loathing and sexual repression.

\section{Conclusions}

Returning to the original question, what are the consequences of applying queer theory to a queer novel? Or is there something queer about running? The answer appears to be yes and no. Warren and her narrator Brown go to some lengths to emphasize Billy's toughness, probably more than would be found in hetero-normative sport literature, and coach Brown maintains that Billy 'has a point to make.' The reader is to appreciate that Billy did not cry following the unfair collision and foul in the 10,000 meters Olympic Trial. Most of the race sequences are completely unremarkable, that is to say that there is nothing queer about running. A queer sport novel is not greatly different from a hetero-normative one when it comes to the competitive running sequences in Front Runner. But some interpretative caution must be taken because the "ordinariness" of Warren's work is considered one of her hallmarks [26]. However, the social contexts for some of the races are plainly charged with animus between pro-gay and anti-gay runners and their respective fans. Warren means for this source of conflict to gain attention in her effort to dramatize the longtime oppression of gay athletes during the 1970s. However, most saliently, there is Brown's speculation that Billy runs hard to prove himself as a man and that his final drive to win the 5000 meters is due to "gay desperation." Perhaps, this is Billy's attempt to etch a rainbow flag into the Olympic symbols. Of course, none of these observations hit as poignantly as the image of a young man, in his athletic prime, tragically bleeding out on track and field's greatest stage.

\section{REFERENCES}

[1] Online Available: http://www.publishingtriangle.org/100nonficbest.asp

[2] B. Distelberg. Mainstream fiction, gay reviewers, and gay male cultural politics in the 1970s, GLQ: A Journal of Lesbian and Gay Studies, 16.3, 389-427, 2010.

[3] J. Gamson. Sexualities, queer theory, and qualitative research. In N. K. Denzin \& Y. S. Lincoln (Eds.). Handbook of Qualitative Research. 2nd ed. (pp. 347-365). Thousand Oaks: Sage Publications, 2000.

[4] J. Gamson. Sexualities, queer theory, and qualitative research. In. N. K. Denzin \& Y. S. Lincoln (Eds.). Handbook of qualitative research. 2nd ed. (pp. 347-365). Thousand Oaks: Sage Publications, 2000.

[5] M. Garber. The return to biology. In I. Morland \& A. Willox (Eds.). Query Theory (pp. 54-69). England, MacMillan 2005.

[6] D. Halperin. Saint Foucault: Towards A Gay Hagiography. USA, Oxford University Press (p.62), 1995.

[7] P. N. Warren. The Front Runner. Wildcat Press, USA, 1974, p. 45.

[8] TFR, p. 45.

[9] TFR, p. 45.

[10] TFR, p. 63.

[11] TFR, p. 63.

[12] TFR, p. 122.

[13] TFR, p. 122.

[14] TFR, p. 170.

[15] TFR, p. 171.

[16] TFR, p. 173.

[17] TFR, p. 174.

[18] TFR, p. 222.

[19] TFR, p. 226.

[20] TFR, p. 227. 
[21] TFR, p. 263.

[22] TFR, p. 263.

[23] TFR, p. 277

[24] TFR, p. 279.

[25] TFR, p. 280.

[26] T. Steuernagle. Contemporary homosexual fiction and the gay rights movement. Journal of Popular Culture, 20.3 Winter 125-134, 1986.
[27] S. Langdon. Gay athletes battle for love on macho road to Olympics. The Advocate, 134, 27 March 1974.

[28] Moriss-Roberts and K. G. Christopher. Jockocracy: Queering Masculinity and Sport. USA: Common Ground, 2013.

[29] The Publishing Triangle. The 100 best lesbian and gay novels. 12 June 2004.

$<$ http://www.publishingtriangle.org/100nonficbest.asp.>

[30] R. Robinson. Running in Literature. USA: Breakaway, 2003.

[31] E. D. Stoneman. Pat Warren explains her insight. The Advocate 134, 27 March 1974. 